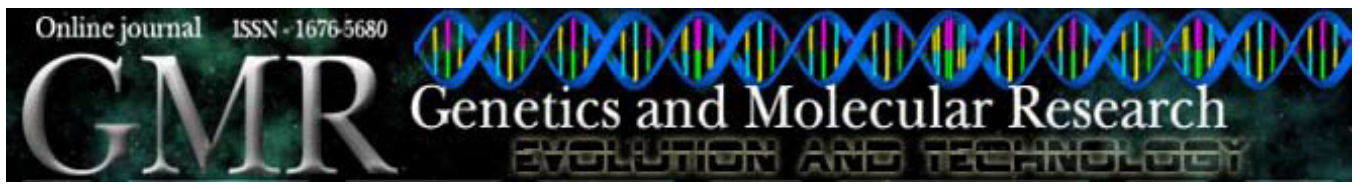

\title{
Genetic variability among natural populations of Zaprionus indianus (Drosophilidae) in the States of São Paulo and Minas Gerais, Brazil
}

\author{
D. Braganholi, M. Bélo, B.W. Bertoni, A.L. Fachin, R.O. Beleboni and \\ S.M. Zingaretti \\ Unidade de Biotecnologia, Universidade de Ribeirão Preto, Ribeirão Preto, \\ SP, Brasil
}

Corresponding author: S.M. Zingaretti

E-mail: szingaretti@unaerp.br

Genet. Mol. Res. 9 (3): 1504-1512 (2010)

Received April 25, 2010

Accepted May 24, 2010

Published August 3, 2010

DOI 10.4238/vol9-3gmr879

\begin{abstract}
Random amplified polymorphic DNA (RAPD) was used to detect polymorphisms among Zaprionus indianus fly populations collected from six municipalities in the States of São Paulo and Minas Gerais, Brazil. This species is an important, recently introduced fruit fly pest of figs and other fruit. Among 21 primers, 16 produced 73 reproducible polymorphic fragments; primer AM-9 produced the greatest number of polymorphic bands (nine), with $52 \%$ genetic variability among populations. Genetic divergence analysis of the $Z$. indianus populations demonstrated two major groups, named Western and Eastern groups. There was greater gene flow within than between groups. The correlation coefficient for genetic and geographic distances (Mantel test) was significant, demonstrating isolation by distance.
\end{abstract}

Key words: Drosophilidae; Polymorphisms; Zaprionus indianus; Random amplified polymorphic DNA 


\section{INTRODUCTION}

Zaprionus indianus (Gupta, 1970) fly was first reported in Brazil by Vilela et al. (1999), in the city of Santa Isabel, SP, in a persimmon (Diospyros sp) orchard. Since then, this fly has been found in various regions of the country, including Porto Alegre, RS (Silva et al., 2005), Valinhos, SP (Pires and Bélo, 2005), the Brazilian central savanna (Cerrado) (Tidon et al., 2003), in many cities in the State of Minas Gerais (Kato et al., 2004), and in Brazilian North and Northeast regions (Santos et al., 2003). This fly has also been reported from Panama, Florida, USA, and Uruguay (Goñi et al., 2001, 2002; Linde, et al., 2006). The rapid spread of this species in the Americas was chiefly due to the favorable conditions for its establishment and development (Stein et al., 2003).

Zaprionus indianus is the most prevalent fly of the Zaprionus genus in some regions of Africa, where it originated; there it has been found on 74 fruit species of 31 botanical families (Lachaise and Tsacas, 1983). In 2002 it was identified in Egypt, and it has became a dominant species in the drosophilid fauna in that country (Yassin et al., 2009). Based on studies of populations from Asia, Africa and South America, using mitochondrial DNA haplotypes of CO-I and CO-II genes, there are two phylogenetic lineages (phylads); phylad I includes some of the African populations and phylad II includes the Atlantic populations, including South and North America and also Madeira, suggesting that during its passage from endemism to cosmopolitanism, Z. indianus went through two independent radiations (Yassin et al., 2008).

In the State of São Paulo, Brazil, Z. indianus is a successful invading species and is now the second most common Drosophilidae species on fruit crops in that state, especially in mango (Mangifera indica), guava (Psidium guajava) and fig (Ficus carica) plantings (Pires and Bélo, 2005). Different from other Drosophilae species, Z. indianus can oviposit on immature fruits, which can cause additional damage to fruits of economic interest (Castro and Valente, 2001). Indeed, losses caused by this species in Brazilian fig crops were responsible for a 50\% decrease in fresh fruit exports in 2000-2001 (Stein et al., 2003). This species is considered by the Brazilian Department of Agriculture to be an A2 quaternary pest and hence infected plants should be removed from orchards, as well as from domestic fruit gardens (Kato et al., 2004). Although $Z$. indianus has been detected in fig plantings, this species also attacks an array of other fruits, thus being considered an opportunistic fly with real chances of becoming a pest of great importance for orchards in Brazil (Vilela et al., 1999).

Because of its economic importance and the rapid geographical expansion of $Z$. india$n u s$, we evaluated its genetic variability in six $Z$. indianus populations from five different municipalities in the State of São Paulo and one in the State of Minas Gerais, distributed in a geographical north-south axis, using random amplified polymorphic DNA (RAPD) techniques.

\section{MATERIAL AND METHODS}

\section{Zaprionus indianus collection}

Adult samples of $Z$. indianus were captured with an entomological net passed over bait prepared with ripe tomato and banana fruit, placed on wooden boxes and protected with stainless steel screens in orchards located in Jaboticabal, SP (21S 15' 17', 48W 19' 20', alt. 605 m), Olímpia, SP (20S 44' 14”, 48W 54' 53”, alt. 506 m), Santa Cruz da Esperança, SP 
(21S 17' 27”, 47W 25' 48”, alt. 612 m), Valinhos, SP (22S 58' 14”, 46W 59' 45”, alt. $660 \mathrm{~m}$ ), Araras, SP (22S 21' 25', 47W 23'03', alt. $629 \mathrm{~m}$ ) and Carneirinho, MG (19S 41' 51', 50W 41' 17 ", alt. $431 \mathrm{~m})$. Forty couples were collected from each population and were transported to the laboratory in $250-\mathrm{mL}$ bottles containing $30 \mathrm{~mL}$ of culture medium, consisting of wheat flour (80 g), corn meal (80 g), gelatin (12 g), Agar (5 g), araruta (12 g), yeast (8 g), corn syrup $(25 \mathrm{~g})$, a $10 \%$ solution of nipagin in $8 \mathrm{~mL}$ alcohol and $2 \mathrm{~mL}$ propionic acid, taxonomically identified and conditioned in an environmental chamber for reproduction and oviposition at $25 \pm 1{ }^{\circ} \mathrm{C}, 70-85 \%$ relative air humidity and a 12 -h constant photoperiod.

\section{Genomic DNA extraction and quantification}

DNA was isolated from five samples of each of the six populations of $Z$. indianus. Samples were constituted of 10 third-instar larvae, totaling 50 individuals per population. Larvae were macerated in $500 \mu \mathrm{L}$ lise SET buffer $(0.15 \mathrm{mM} \mathrm{NaCl} ; 0.02 \mathrm{mM}$ Tris and $1 \mathrm{mM}$ EDTA, $\mathrm{pH}$ 8.0), $18 \mu \mathrm{L}$ proteinase K $(10 \mathrm{mg} / \mathrm{mL})$ and $22 \mu \mathrm{L} \mathrm{25 \%} \mathrm{SDS} \mathrm{solution.} \mathrm{Samples}$ were kept at $55^{\circ} \mathrm{C}$ for $2 \mathrm{~h}$, after which $430 \mu \mathrm{L} \mathrm{NaCl}(6 \mathrm{M})$ was added. Subsequently, samples were centrifuged at $12,000 \mathrm{~g}$ for $10 \mathrm{~min}$ at $4^{\circ} \mathrm{C}$, the supernatant was transferred to another tube containing $40 \mu \mathrm{L}$ sodium acetate $(3 \mathrm{M})$ and $600 \mu \mathrm{L}$ cold isopropanol. Samples were kept in a freezer at $-20^{\circ} \mathrm{C}$ for $20 \mathrm{~min}$ and subsequently centrifuged at $12,000 \mathrm{~g}$, for $15 \mathrm{~min}$, at $4{ }^{\circ} \mathrm{C}$. The pellet was rinsed in $70 \%$ ethanol and resuspended in Milli-Q water. DNA was quantified with a spectrophotometer $(\lambda=260$ and $280 \mathrm{~nm})$ and its integrity analyzed by electrophoresis on a $1 \%$ agarose gel $(\mathrm{w} / \mathrm{v})$, stained with ethidium bromide $(0.5 \mu \mathrm{g} / \mathrm{mL})$, in $1 \mathrm{X}$ TBE buffer at $100 \mathrm{~V}$.

\section{Determination of variability among strains by polymerase chain reaction using random primers (RAPD)}

Twenty-one random primers (Operon Life Technology and Biosynthesis Incorporated) were used to examine divergence among $Z$. indianus strains. Each of the amplifications was done to a final volume of $30 \mu \mathrm{L}$, containing $30 \mathrm{ng}$ genomic DNA, $2 \mathrm{U}$ Taq polymerase (Invitrogen), 10 pmol primers, $3 \mathrm{mM} \mathrm{MgCl}, 100 \mu \mathrm{M}$ of each dNTP (Promega), and a specific reaction buffer. Amplifications were carried out in a PTC-100 thermocycler (MJ-Research, Inc.), under the following conditions: $2 \mathrm{~min}$ at $94^{\circ} \mathrm{C}$ for initial denaturation, annealing at $37^{\circ} \mathrm{C}$ for $1 \mathrm{~min}$, extension at $72^{\circ} \mathrm{C}$ for $2 \mathrm{~min}$, and 32 cycles for $10 \mathrm{~s}$ of denaturation at $94^{\circ} \mathrm{C}, 20 \mathrm{~s}$ of annealing at $40^{\circ} \mathrm{C}$, an extension period of $2 \mathrm{~min}$ at $72^{\circ} \mathrm{C}$, and finally another extension for $5 \mathrm{~min}$ at the same temperature. RAPD fragments were separated by electrophoresis on $1.5 \%$ ethidium bromidestained agarose gel $(0.5 \mu \mathrm{g} / \mathrm{mL})$, at $100 \mathrm{~V}$ on $1 \mathrm{X}$ TBE, using a molecular weight marker of $100 \mathrm{bp}$ (DNA Ladder, GE Healthcare) and photographed using Image Master VDS, Pharmacia Biotech.

\section{Genetic variability analysis}

An analysis was carried out to estimate the evolutionary relationship among populations, based on the matrix of presence (1) or absence (0) constructed from the amplification pattern observed on the agarose gel. 
Binary data obtained from RAPDs were utilized to estimate allele frequencies, with a correction developed by Lynch and Milligan (1994). A descriptive analysis of total variability was next made by calculating the percentage of polymorphic loci and gene flow using the POPGENE software (Yeh et al., 1999). AMOVA was utilized for the decomposition of the total genetic variance into its components between and within the populations, allowing evaluation of variability structure, as proposed by Excoffier et al. (1992), using the programs TFPGA (Miller, 1997), AMOVA-PREP 1.01 (Miller, 1998) and WINAMOVA 1.04 (Excoffier et al., 1992).

Nei's (1978) distance was used for genetic distance calculations in a type UPGMA grouping analysis, to examine the genetic divergence among the populations; this helps determine the source of genetic variability. The correlation coefficients for genetic and geographic distance were obtained with the Mantel test using the GENES software (Cruz, 2008).

\section{RESULTS}

Twenty-one random primers were used to analyze the $Z$. indianus strain variability, of which 16 produced reproducible and well-defined polymorphic bands (Table 1). The nucleotide sequence and the total number of bands (mono- and polymorphic) produced by amplification were also determined for each primer (Table 1). Seventy-four bands were obtained, of which 73 were polymorphic and 1 monomorphic. The number of bands amplified by each primer varied from three to nine, with a mean of 4.6, and variable sizes of 400 to $1300 \mathrm{bp}$. Primer AM-9 produced nine amplified bands and was followed by primers AM-6 with seven and AM-1, AM-4, AM-11, which produced five polymorphic bands each.

\begin{tabular}{|c|c|c|c|c|}
\hline \multirow[t]{2}{*}{ Primers } & \multirow[t]{2}{*}{ Nucleotide sequences (5' to 3') } & \multicolumn{3}{|c|}{ Bands } \\
\hline & & Polymorphic & Monomorphic & Total \\
\hline AM-1 & AATCGGGCTG & 5 & 0 & 5 \\
\hline AM-2 & CAGGCCCTTC & 4 & 0 & 4 \\
\hline AM-3 & AGGGGTCTTG & 4 & 0 & 4 \\
\hline AM-4 & TGCCGAGCTG & 5 & 0 & 5 \\
\hline AM-5 & GTGACGTAGC & 6 & 0 & 6 \\
\hline AM-6 & AGGGGTCTTG & 7 & 0 & 7 \\
\hline AM-7 & GTGAGCTAGG & 3 & 1 & 4 \\
\hline AM-8 & AGGTGACCGT & 3 & 0 & 3 \\
\hline AM-9 & GGACTGGAGT & 9 & 0 & 9 \\
\hline AM-10 & GTTGCGATCC & 4 & 0 & 4 \\
\hline AM-11 & TGGGGGACTC & 5 & 0 & 5 \\
\hline AM-14 & AGCGTCACTC & 5 & 0 & 5 \\
\hline AM-16 & GTCCACACGG & 3 & 0 & 3 \\
\hline AM-17 & CCCCGATGGT & 3 & 0 & 3 \\
\hline AM-19 & TCGCCCAGTG & 4 & 0 & 4 \\
\hline AM-21 & TGCCGAGCTG & 3 & 0 & 3 \\
\hline Total & & 73 & 1 & 74 \\
\hline
\end{tabular}

A sample pattern of the random amplified fragments obtained for all populations using different primers is shown in Figure 1. The profile of the bands produced by amplification allowed the development of a dendogram (Figure 2). 


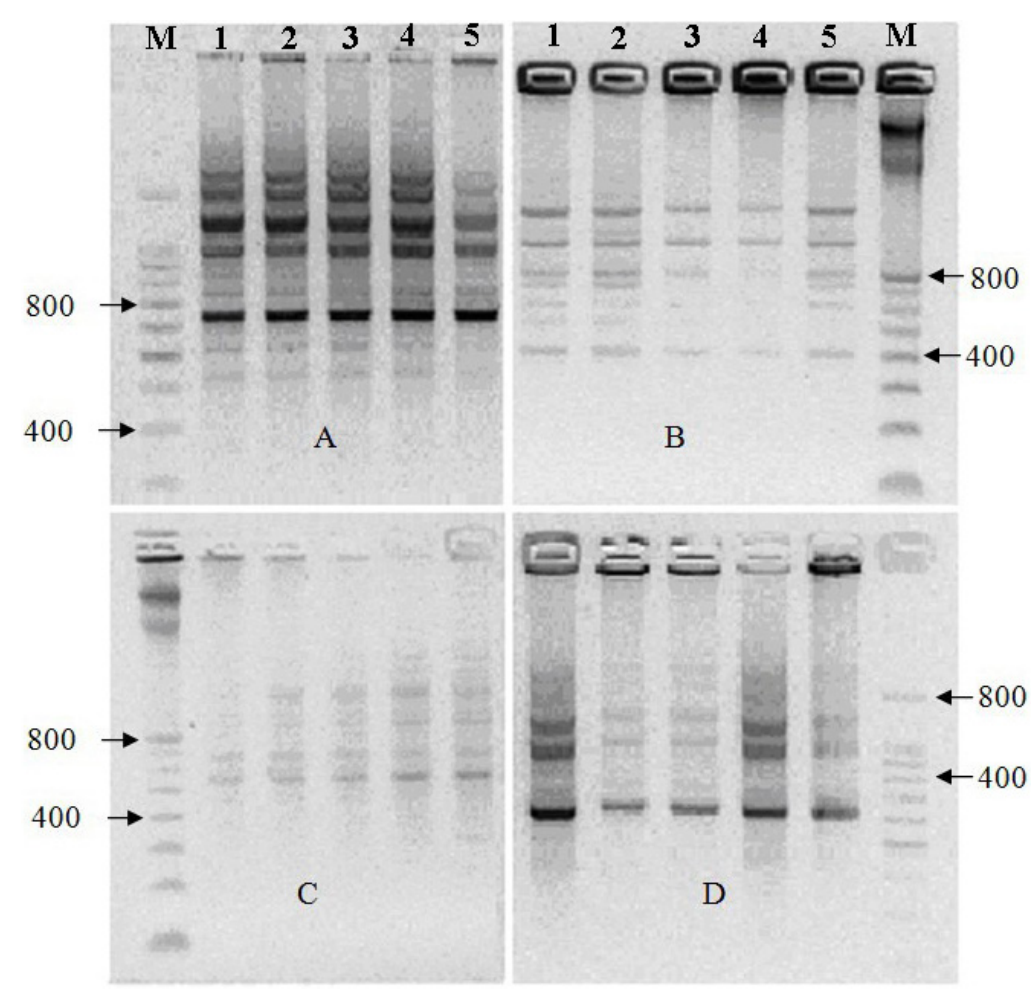

Figure 1. Electropherogram of the randomly amplified fragments in DNA samples (lanes 1-5) of the four populations using random primers. A. Jaboticabal, SP, using the AM-1 primer. B. Santa Cruz da Esperança, SP, using the AM-6 primer. C. Carneirinho, MG, using the AM-3 primer; D. Araras, SP, using the AM-4 primer. M = molecular weight marker $=100 \mathrm{bp}$ (GE Healthcare).
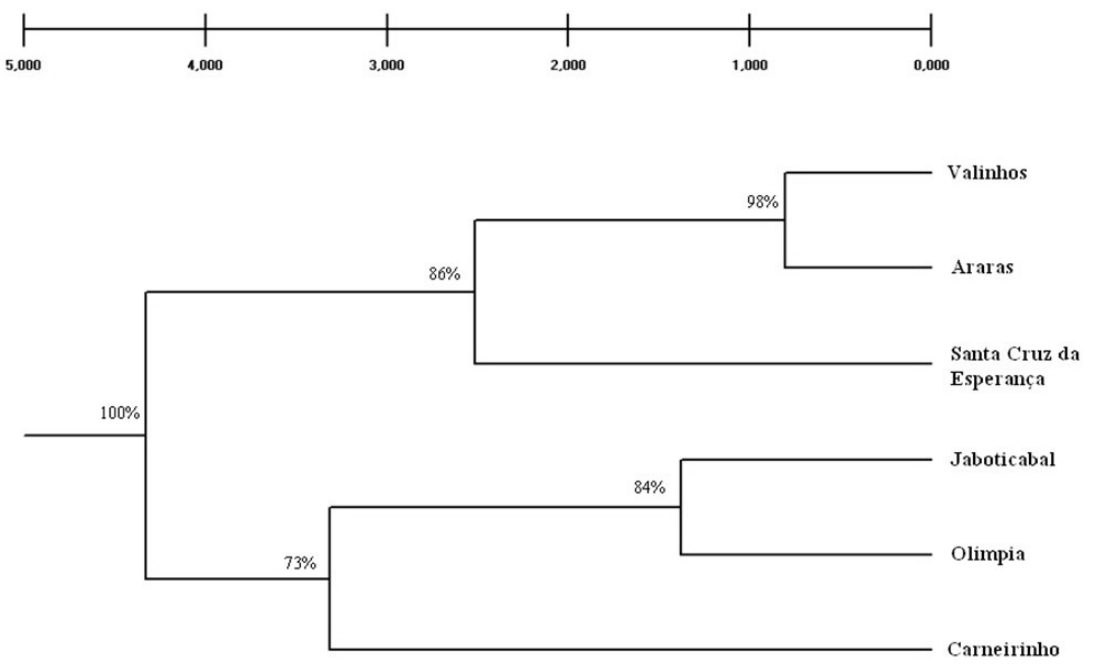

Figure 2. Genetic divergence pattern based on RAPD markers among six populations of Zaprionus indianus, defined by UPGMA grouping, based on Nei’s (1978) genetic distances. 
The genetic variability among $Z$. indianus populations resulted in a ramification pattern defined by the UPGMA method, based on Nei's genetic distance (1978) and determined by pairing populations. The genetic distance range was from 0.0804 to 0.6086 (Table 2).

Table 2. Geographic localization and genetic distances among populations of Zaprionus indianus, according to Nei (1978) (below the diagonal) and geographic distances in kilometers (above the diagonal).

\begin{tabular}{|c|c|c|c|c|c|c|c|c|c|}
\hline \multirow[t]{2}{*}{ Population } & \multirow[t]{2}{*}{ Longitude } & \multirow[t]{2}{*}{ Latitude } & \multirow[t]{2}{*}{ Altitude (m) } & \multicolumn{6}{|c|}{ Distance between populations } \\
\hline & & & & $\mathrm{Jab}$. & Olímp. & Carn. & SCE & Val. & Ar. \\
\hline Jab. & $-48^{\circ} 19^{\prime}$ & $-21^{\circ} 15^{\prime}$ & 605 & $* * * * *$ & 84.01 & 301 & 99.77 & 234 & 154 \\
\hline Olímp. & $-48^{\circ} 54^{\prime}$ & $-20^{\circ} 44^{\prime}$ & 506 & 0.1379 & $* * * * *$ & 219 & 166 & 317 & 240 \\
\hline Carn. & $-50^{\circ} 41^{\prime}$ & $-19^{\circ} 41^{\prime}$ & 431 & 0.4492 & 0.2140 & $* * * * *$ & 383 & 526 & 453 \\
\hline SCE & $-47^{\circ} 25^{\prime}$ & $-21^{\circ} 17^{\prime}$ & 612 & 0.3137 & 0.4001 & 0.6086 & $* * * * *$ & 193 & 116 \\
\hline Val. & $-46^{\circ} 59^{\prime}$ & $-22^{\circ} 58^{\prime}$ & 660 & 0.4618 & 0.3918 & 0.3940 & 0.1999 & $* * * * *$ & 79.3 \\
\hline Ar. & $-47^{\circ} 23^{\prime}$ & $-22^{\circ} 21^{\prime}$ & 629 & 0.5254 & 0.4139 & 0.3836 & 0.3030 & 0.0804 & $* * * * *$ \\
\hline
\end{tabular}

Jab. = Jaboticabal, SP; Olímp. $=$ Olímpia, SP; Carn. = Carneirinho, MG; SCE $=$ Santa Cruz da Esperança, SP; Val. $=$ Valinhos, SP; Ar. $=$ Araras, SP.

\section{Genetic frequency and variability}

Analysis of molecular variance (Table 3 ) showed that the total genetic variability between strains was $52.4 \%$, whereas within strains it was $47.6 \%$ and the $\mathrm{F}_{\mathrm{st}}$ was 0.525 .

Table 3. Analysis of molecular variance for six Zaprionus indianus populations based on amplified DNA
fragments.
\begin{tabular}{lrrrrcccc}
\hline Source of variation & d.f. & S.S. & S.A.S. & Components of variance & \% Total variation & P & $\mathrm{F}_{\text {st }}$ \\
\hline Between populations & 5 & 230.36 & 46.07 & 7.79 & 52.37 & $<0.001$ & 0.524 \\
Within populations & 24 & 170.20 & 7.09 & 7.09 & 47.63 & - & - \\
Total & 29 & 400.56 & & & & \\
\hline
\end{tabular}

d.f. $=$ degrees of freedom; S.S. $=$ sum of squares; S.A.A. = sum of average squares.

The descriptive statistics on the genetic variability of populations, obtained with the POPGENE software (Yeh et al., 1999) indicated less variability for the Santa Cruz da Esperança population (14.1\%), followed by Carneirinho (31.0\%), Olimpia (43.7\%), Jaboticabal and Valinhos (47.9\%), and a higher variability for Araras (52.1\%).

The dendogram showed two main groupings (Figure 2), one contains populations from Carneirinho, Olimpia and Jaboticabal (Western group) and the other includes Araras, Valinhos and Santa Cruz da Esperança populations (Eastern group). In each of the two groups, two populations showed more similarity: Valinhos and Jaboticabal in the Western group and Araras and Valinhos in the Eastern group. The gene flow for Western and Eastern groups was $\mathrm{Nm}=0.4562$ and 0.4460; the gene flow inside the groups was higher than between them $(\mathrm{Nm}=0.3727)$.

The correlation coefficient for genetic and geographic distances, obtained with the Mantel test, was significant $(\mathrm{r}=0.52 ; \mathrm{P}<0.05$ with 5000 permutations) suggesting isolation by distance (Figure 3). 


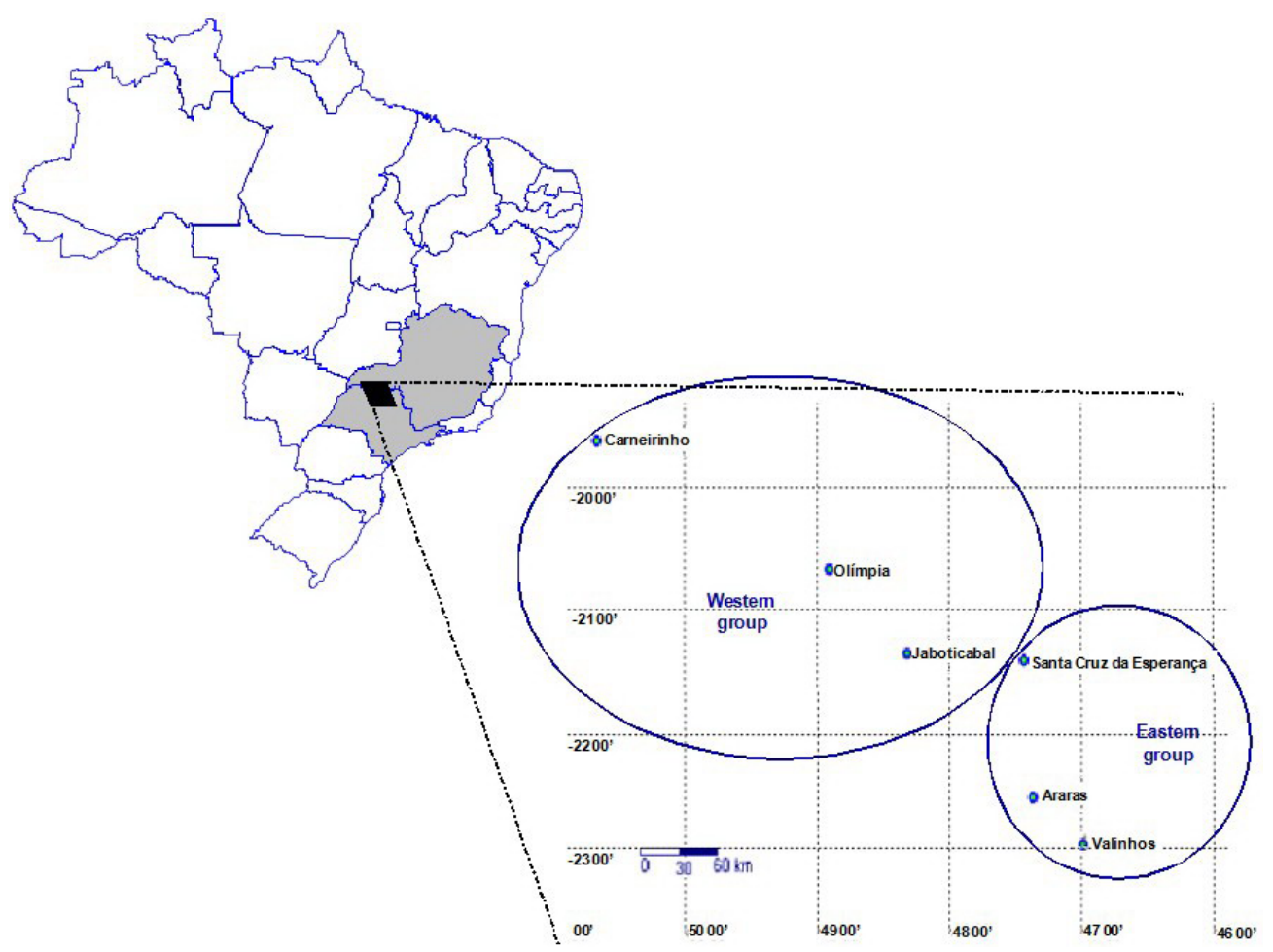

Figure 3. Map showing the distribution of the Zaprionus indianus populations. Ellipses indicate the groups formed by UPGMA clustering, based on Nei's (1978) genetic distances.

\section{DISCUSSION}

Studies of the dynamics of the colonization of flies in fruit orchards are of relevance, not only because of economic considerations, as a result of damage to fruit, but also because of biological aspects. It is possible that crop infestation by $Z$. indianus and the increasing range of this introduced species will threaten the stability of pre-established Drosophila communities, which are very rich in number of species.

Investigations have been made of colonization dynamics and genetic variability of $Z$. indianus populations in Brazil, including several studies using genetic markers such as allozymes (Mattos-Machado et al., 2005), chromosomal inversion polymorphisms (Ananina et al., 2007), and quantitative traits (David et al., 2006; Loh et al., 2008). Ours is, to the best of our knowledge, the first study of genetic variability of $Z$. indianus Brazilian populations based only on molecular markers.

We found higher genetic variability among than within the fly populations. In general, low variability has been detected in American populations of $Z$. indianus samples in comparisons of isofemale lines from African and American populations (David et al., 2006) and in studies of mitochondrial DNA (Yassin et al., 2009) from Egyptian samples. Mattos-Machado et al. (2005) reported low variability in Brazilian populations compared to African and Asiatic samples, based on allozyme analyses. However, studies of chromosomal inversion carried out by Ananina et al. (2007) also revealed five new inversions in Brazilian populations, which were therefore found to 
be more polymorphic than Indian populations. High variability was also observed in wing size and shape in relation to growth temperature in two natural populations, Rio de Janeiro, Brazil, and São Tomé Island, near Africa (Loh et al., 2008). Low variability was only found in Santa Cruz da Esperança, SP. It is possible that the population in Santa Cruz, SP, has been subjected to particular selective forces or adaptive differentiation caused by anthropomorphic factors.

When we examined the geographic distribution of the populations, we found two groups, based on genetic distance, including cities at different latitudes (Figure 3). Our results indicate that the six populations of $Z$. indianus are genetically related to their geographical distributions; the closer the two populations, the more genetically similar they were. An exception to this rule was observed when we compared populations of Santa Cruz da Esperança and Jaboticabal, SP; despite being at the same latitude, they had different variabilities of 14.1 and $47.9 \%$, respectively. Although Santa Cruz da Esperança and Jaboticabal are only $100 \mathrm{~km}$ from each other, they are separated by a large sugarcane monoculture, which could explain the difference.

Latitudinal differentiation for $Z$. indianus has not been found in Brazilian populations, based on quantitative traits, such as body size, thoracic bristles (David et al., 2006) and chromosomal polymorphism (Ananina et al., 2007). However, it is possible that the $Z$. indianus flies, recently introduced in Brazil (Vilela et al., 1999), have been undergoing local differentiation processes, due to selective pressures of natural selection. Based on our data, the two groups of flies demonstrate signs of an incipient selection process, which may subsequently lead to a cline, as Alves and Bélo (2002) described for a nearby region, when they examined Musca domestica populations. Similar results had been observed in Egypt populations, based on mitochondrial DNA and chromosomal inversion polymorphism, despite the low genetic variability that was found (Yassin et al., 2009).

We found that the populations could be classified into two clearly different groups, which we called western and eastern patterns, based on geographic distribution (Figure 3). The higher value for gene flow between the two groups (western and eastern) compared to the value for all populations is also indicative of population structure. Genetic and geographic correlation data support the distance isolation model, although the $\mathrm{F}_{\text {st }}$ value determined for our study was high (0.524). It is known that $\mathrm{F}_{\text {st }}$ above 0.15 is an indication of differentiation of fragmented populations (Frankham et al., 2006). Similar results were reported previously (Mattos-Machado et al., 2005), in a study of allozyme variability in populations of $Z$. indianus collected from Poços de Caldas, MG, and Brasília, DF, with an observed $\mathrm{F}_{\mathrm{st}}$ of 0.105 , although there was no correlation with geographic distance. Behavioral and ecological factors, such as temperature, latitude and longitude, may be responsible for the low gene flow values (0.3727) and high $\mathrm{F}_{\text {st }}$ between the two groups, which may be responsible for the population structure that we observed.

\section{ACKNOWLEDGMENTS}

Research supported by Fundação de Amparo à Pesquisa do Estado de São Paulo (FAPESP), project \#07/03296-7.

\section{REFERENCES}

Alves SM and Bélo M (2002). Morphometric variations in the housefly, Musca domestica (L.) with latitude. Genetica 115: 243-251.

Ananina G, Rohde C, David JR, Valente VL, et al. (2007). Inversion polymorphism and a new polytene chromosome map of Zaprionus indianus Gupta (1970) (Diptera: Drosophilidae). Genetica 131: 117-125. 
Castro FL and Valente VLS (2001). Zaprionus indianus is invading Drosophilid communities in the southern Brazilian city of Porto Alegre. Dros. Inf. Serv. 84: 15-17.

Cruz CD (2008). Programa GENES: Diversidade Genética. Universidade Federal de Viçosa, Viçosa.

David JR, Araripe LO, Bitner-Mathé BC, Capy P, et al. (2006). Quantitative trait analysis and geographic variability of natural populations of Zaprionus indianus, a recent invader in Brazil. Heredity 96: 53-62.

Excoffier L, Smouse PE and Quattro JM (1992). Analysis of molecular variance inferred from metric distances among DNA haplotypes: application to human mitochondrial DNA restriction data. Genetics 131: 479-491.

Frankham R, Ballou JD and Briscoe DA (2006). Introduction to Conservation Genetics. 6th edn. Cambridge University Press, Cambridge.

Goñi B, Fresia P, Calviño M, Ferreiro MJ, et al. (2001). First record of Zaprionus indianus Gupta, 1970 (Diptera, Drosophilidae) in southern localities of Uruguay. Dros. Inf. Serv. 84: 61-64.

Goñi B, Martinez ME, Techera G and Fresia P (2002). Increased frequencies of Zaprionus indianus Gupta, 1970 (Diptera, Drosophilidae) in Uruguay. Dros. Inf. Serv. 85: 75-80.

Kato CM, Foureaux LV, César RA and Torres MP (2004). Ocorrência de Zaprionus indianus, Gupta, 1970, (Diptera: Drosophilidae) no Estado de Minas Gerais. Cienc. Agrotec. 28: 454-455.

Lachaise D and Tsacas L (1983). Breeding Sites in Tropical African Drosophilids. In: The Genetics and Biology of Drosophila (Ashbumer M, Carson HL and Thompson JN Jr, eds.). Academic Press, London, 22-232.

Linde KVD, Steck GJ, Hibbcerd K, Birdsley JS, et al. (2006). First records of Zaprionus indianus (Diptera: Drosophilidae), a pest species on commercial fruits from Panama and the United States of America. Fla. Entomol. 89: 402-404.

Loh R, David JR, Debat V and Bitner-Matha BC (2008). Adaptation to different climates results in divergent phenotypic plasticity of wing size and shape in an invasive drosophilid. J. Genet. 87: 209-217.

Lynch M and Milligan BG (1994). Analysis of population genetic structure with RAPD markers. Mol. Ecol. 3: 91-99.

Mattos-Machado T, Solé-Cava AM, David JR and Bittner-Mathé BC (2005). Allozyme variability in an invasive drosophilid, Zaprionus indianus (Diptera: Drosophilidae): comparison of a recently introduced Brazilian population with Old World populations. Ann. Soc. Entomol. Fr. 41: 7-13.

Miller MP (1997). Tools for populations' genetics analyses (Computer software distributed by the author). Available at [http://www.marksgeneticsoftware.net/tfpga.htm]. Accessed February 2, 2005.

Miller MP (1998). AMOVA-PREP 1.01. A Program for the Preparation of ANOVA Input Files from Dominant Marker Raw Data (Computer software distributed by the author). Available at [http://www.marksgeneticsoftware.net/_vti_ bin/shtml.exe/amovaprep.htm]. Accessed February 2, 2005.

Nei M (1978). Estimation of average heterozygosity and genetic distance from a small number of individuals. Genetics 89: 583-590.

Pires DJ and Bélo M (2005). Flies collected in orchards. Dros. Inf. Serv. 88: 69-72.

Santos JF, Rieger TT, Campos SRC, Nascimento ACC, et al. (2003). Colonization of Northeast Region of Brazil by the drosophilid flies Drosophila malerkotiliana and Zaprionus indianus, a new potential insect pest for Brazilian fruitculture. Dros. Inf. Serv. 86: 92-95.

Silva NM, Fantinel CC, Valente VLS and Valiati VH (2005). Population dynamics of the invasive species Zaprionus indianus (Gupta) (Diptera: Drosophilidae) in communities of drosophilids of Porto Alegre City, Southern of Brazil. Neotrop. Entomol. 34: 363-374.

Stein CP, Teixeira EP and Novo JPS (2003). Aspectos biológicos da mosca do figo, Zaprionus indianus Gupta, 1970 (Diptera: Drosophilidae). Entomotropica 18: 219-221.

Tidon R, Leite DF and Leão BFD (2003). Impact of the colonisation of Zaprionus (Diptera, Drosophilidae) in different ecosystems of the Neotropical Region: 2 years after the invasion. Biol. Conserv. 112: 299-305.

Vilela CR, Teixeira EP and Stein CP (1999). Nova praga nos figos: Zaprionus indianus Gupta, 1970. Inf. Soc. Entomol. Bras. 24: 2.

Yassin A, Capy P, Madi-Ravazzi L, Ogereau D, et al. (2008). DNA barcode discovers two cryptic species and two geographical radiations in the invasive drosophilid Zaprionus indianus. Mol. Ecol. Resour. 8: 491-501.

Yassin A, Borai F, Capy P, David JR, et al. (2009). Evolutionary genetics of Zaprionus. II. Mitochondrial DNA and chromosomal variation of the invasive drosophilid Zaprionus indianus in Egypt. Mitochondrial DNA 20: 34-40.

Yeh FC, Yang R-C and Boyle T (1999). POPGENE Version 1.31. Microsoft Window-based Freeware for Population Genetic Analysis. Quick User Guide. University of Albert, Centre for International Forestry Research. Available at [http://www.ualberta.ca/ fyeh/popgene.pdf]. Accessed February 2, 2002. 